\title{
Research on Innovation of Financial Management Talents Training Model Based on the Perspective of Professional Ability Supply and Demand
}

\author{
Weishuang $\mathrm{Xu}^{1, \mathrm{a} \text {, * }}$ \\ ${ }^{1}$ College of Economics and Management, Qilu Normal University, Jinan, Shandong, China \\ axwsjn@163.com
}

Keywords: Financial Management Specialty; Professional Ability Supply and Demand; Talents Training Model; Innovation

\begin{abstract}
Theoretically, financial management specialty has the advantage of both accounting specialty and finance specialty. Financial management is the advanced stage of corporate financial activities management. Therefore, the graduates of financial management specialty should be praised by the social demand subject. The social demand subject also has reason to raise higher professional ability requirements for the graduates. However, there is a great difference between the supply and demand of professional ability under the existing talent training mode because many colleges and universities that set financial management specialties are not sure about the professional ability requirements of social demand subject. Financial management graduates are in a more embarrassing situation in employment market. Based on this, on the base of analyzing the status and causes of professional ability supply and demand of financial management specialty, this paper proposes the basic idea of talents training model innovation of financial management specialty from the aspects of determination talent training goal, revision professional talent training program, respect student's central status and innovative teaching activities.
\end{abstract}

\section{Introduction}

According to statistics, a total of 616 undergraduate colleges and universities in China had set up financial management specialty by the end of 2017. Theoretically, financial management specialty has the advantage of both accounting specialty and finance specialty. Financial management is the advanced stage of corporate financial activities management. Therefore, the graduates of financial management specialty should be praised by the social demand subject. The social demand subject also has reason to raise higher professional ability requirements for the graduates. However, there is a great difference between the supply and demand of professional ability under the existing talent training mode because many colleges and universities that set financial management specialties are not sure about the professional ability requirements of social demand subject. Financial management graduates are in a more embarrassing situation in employment market. Hu Xiaoping (2016) [1] believes that the employment market of financial management specialty graduates presents two opposite situations: insufficient demand for low-level talent and strong demand for high-level talent. The structural contradiction between talent supply and demand is relatively prominent. Wang Xiaopu (2016) [2] believes that the graduates of financial management specialty lack clear vocational orientation and professional skills. That leads the graduates have no place in small and micro enterprises. In July 2010, the Ministry of Education issued" the Outline of National Medium and Long Term Education Reform and Development Plan (2010-2020)". It clearly pointed out that professional ability training rather than knowledge imparting should be placed in a due height and become an important standard for evaluating talents quality. Based on this, on the base of analyzing the status and causes of professional ability supply and demand of financial management specialty, this paper proposes the basic idea of talents training model innovation of financial management specialty from the aspects of professional ability supply and demand. 


\section{The Status of Financial Management Specialty Professional Ability Supply and Demand}

The status of professional ability supply. The professional ability supply is influenced by many factors such as professionals training objectives of and talent training programs. Financial management specialty has the advantages of both accounting specialty and the finance specialty in theory. Therefore, in the practice of professional talents training, we want to learn and integrate the training goals and training programs of accounting specialty and the finance specialty. As a result, it lacks the talent training characteristics of itself. The supply of professional abilities is not satisfactory. According to the author's experience in teaching financial management for many years, the supply of professional abilities in financial management specialty is mainly reflected in the following aspects: (1) Although the emphasis has always been placed on training "compound" or "professional" talents, but the comprehensive quality and professional ability of students have not been improved. (2) Theoretical knowledge imparting is more important than the cultivation of the ability of analyzing and solving practical problems with theoretical knowledge. (3) Students' innovation and entrepreneurial ability, communication and coordination ability, sustainable development ability and professional ethics have not been mentioned as deserved. (4) Students lack obvious career planning and management capabilities and have no definite career direction and orientation for future career development.

The status of professional ability demand. The demand of social demand subjects for the professional ability of financial management graduates may vary because of the difference in the job position. In general, the demand of social demand subject for graduates' professional ability will involve all aspects of career planning and management. Jie Maohua and Wu Qian (2013) [3] think that employers most focus on comprehensive quality, practical working ability, cooperation spirit, professional knowledge and communicative competence. Wang Xiaopu (2016) believes that the ability and quality of financial management talents required by enterprises mainly include theoretical foundation, learning ability, communication ability, organizational management ability, operation ability and moral quality. Xu Weishuang (2018) [4] thinks that sustainable development ability, logical thinking ability, communication ability, professional ability, innovation ability and professional quality are the most important professional abilities valued by social demand subjects.

Analysis of the difference between professional ability supply and demand. Through the analysis of the current supply and demand situation of financial management specialty professional ability, the difference between professional ability supply and demand is mainly reflected in the following aspects: (1) There is a big difference between the insufficient supply of comprehensive ability and professional ability and the strong demand of social demand subjects. (2) There is a big difference between the relatively stable theoretical knowledge supply and the dynamic application ability and innovation ability demand. (3) There is a big difference between students' unclear career orientation and career direction and the need for targeted posts of social demand subjects. In general, the professional ability supply is not conducive to the career planning and expansion of graduate and professional ability demand is more required from the perspective of career management.

\section{The Causes Analysis of the Differences between Professional Ability Supply and Demand of Financial Management Specialty}

Talent training goal is not clear. In view of the characteristics of financial management specialty, its talent training goal always tries to have the advantages of both accounting specialty and finance specialty talents training goal at the same time. Therefore, the talent training goal has been rocking in the "compound talents" and "professional talents". Wang Pei (2015) [5] believes that the training goals of financial management specialty are relatively ambiguous. It hopes to integrate accounting and finance in knowledge and take into consideration enterprises and financial institutions in employment. However, contrary to expectations, financial management specialty has not been able to be readily available between accounting and finance. In the contrary, the professional tendency of financial management leads to its content is ambiguous. It was expected to be a "general talent" in 
the ideal but in the end it was only a "miscellaneous family" with a little knowledge of everything. Then it is neglected by students and employment market is inevitable.

Talent training program is out of line with social needs. Talent training program is an important basis for achieving talent training goal. However, talents training programs of financial management specialty in many colleges and universities are not reasonable. (1) Based on the perspective of colleges and universities themselves. At present, talent training program of financial management specialty in many colleges and universities has also been integrated accounting specialty and financial specialty. There are two defects in the talents training program established by this model: (1) The first is that professional core courses are not focused on accounting specialty or emphasis on finance specialty. That leads to a lack of characteristics in the construction of financial management specialty. The second is that the intersecting and duplication among the professional courses is very serious. That not only wastes the resources but also is unfavorable to the cultivation and promotion of students' quality (Wu Keping, 2016) [6]. (2) Based on the perspective of other stakeholders. The ways of stakeholders participation in the design of talent training program are limited and stakeholders also have no enough enthusiasm. That results in a disconnect between the design of talent training program and the needs of stakeholder and further affects the differences of professional abilities supply and demand.

Teaching activities deviate from the requirements of social demand subjects. Teaching activities are an important way and means to implement the talent training program. But Luo Fukai (2017) [7] believes that there are two problems in the teaching activities of financial management in colleges and universities: The first is that students' unnecessary learning burden is too heavy; the second is that the situation of non-professional courses replacing professional courses is more serious. The reason is: (1) The teaching content and assessment system is unreasonable which aggravates students' learning burden. (2) The backward of teaching model and teaching resources led to the necessary professional courses have not been opened. (3) Students' central position and independent choice right have not been fully respected and embodied.

\section{The Basic Thinking of Talents Training Mode Reform of Financial Management Specialty}

Clear professional talents training goals. Talents raining goal is the most fundamental factor that affects talent training quality. Therefore, it is necessary to clear talents training goal in order to reduce the difference between professional ability supply and demand. Li Ying (2014)[8] believes that talent training goals of financial management specialty should be located "accounting" as the base and with "finance" as the core, integrate rational thinking ability, application ability, learning ability and comprehensive business capability as a whole. Luo Fukai (2017) believes that talent training goals of financial management specialty should be student-centered, follow the learning intention of the educated and take meeting students' future career needs as the starting point. In short, professional talents training goal must clearly define students' central status and the specific requirements of professional ability training. It must reflect the characteristics of financial management specialty and no longer vacillate between accounting specialty and finance specialty.

Revise talent training program according to the requirements of talent training goals and post professional ability. The talent training program is a necessary guarantee to achieve talent training goal. colleges and universities must completely abandon the old ideas of reference and integration and effectively formulate targeted talent training programs based on the talent training goal and the requirement of professional abilities. Colleges and universities must completely abandon the old ideas of learning and integrating used in past and set out a targeted talents training program from the requirements of talent training goals and post professional ability. Li Zhitang (2017) [9] believes that talent training program should be oriented toward professional needs, aim at professional ability and design the goals, specifications, standards and various training links. It is necessary to highlight the connection and role of each link to the training of professional ability and organize teaching activities around ability training. (1) The curriculum setting should reflect the characteristics of "subject-based" and the "ability-based" and set core courses around subject construction and core professional ability training. So the courses opened can embody the talent 
training characteristics. (2) Attract other stakeholders including social demand subjects to participate in the revision of talent training program. On the one hand, it can benefit by mutual discussion and make the revised talent training program more in line with the needs of stakeholders. On the other hand, it also provides guidance for colleges and universities to rationally allocate teaching resources. If necessary, it can reasonably use other stakeholders' resources as a necessary supplement to teaching resources. .

Fully respect students' central position and independent choice. To narrow the gap of professional ability supply and demand between university and social demand subjects, we should first narrow the gap of professional ability supply and demand between university and students. In current model of talent training, students are relatively passive and they have no right to chose courses, teaching teachers, teachers' teaching methods and examination evaluation methods. Therefore, many courses actually opened in colleges and universities are not required by the students. The content of teacher's teaching is not the content of students need. This not only wastes the teaching resources but also causes the misplacement of professional ability supply and demand between universities and students. Therefore, students' central status and independent choice right must be fully respected and reflected under the new talent training model. Fortunately, the point system reform provides an opportunity for this. Under the point system talent cultivation system, students can independently choose courses and teachers according to their own characteristics and future career plans and independently choose learning form and examination evaluation forms. This not only fully respects students' central position in the talents training but also gives the teachers certain pressure. That is helpful to guide teachers to improve talent training quality.

Innovate teaching activities based on the perspective of professional ability training. Teaching activities are the product of teaching mode. The traditional teaching mode ignores the training and evaluation of students' professional ability, which affects students' ability to adapt to the changes of external economic environment. Therefore, traditional teaching activities must be innovated from the perspective of professional ability training. (1) Formulate teaching content based on professional ability needs. At present, many teachers' teaching content is still based on textbooks rather than professional ability training. This not only wastes limited teaching resources but also deepens students' disgust to the specialty. Therefore, professional ability training must be conscientiously raised to its proper position under the new talent training model. (2) Implement problem-oriented teaching methods. The problem-oriented teaching method focuses on training students' ability to raise questions, analyze and solve problems. This can not only broaden students' knowledge level but also improve their logically thinking ability and sustainable development ability. (3) Form an assessment system based on ability evaluation. The ability-oriented assessment system should be diverse because the forms of ability are diverse, such as the form of case analysis, the form of obtaining professional qualifications, participating in discipline competition and innovation and entrepreneurship competition. (4) Equipped with necessary teaching resources. The innovation of teaching model will inevitably require corresponding teaching resources as guarantees, such as the relevant guidance and guarantee system, high-quality teacher resources and practical teaching conditions, perfect library resources and necessary funding guarantees etc..

\section{Acknowledgements}

This paper is funded by Key Topics of Qilu Normal University "Ability Model Talents Training Mode Reform of Financial Management Specialty" and Shandong Province Undergraduate College Teaching Reform Project "Research on Integrated Path of Professional Competence, Professional Qualification and Talent Training Program--Taking Accounting Profession as an Example".

\section{Reference}

[1] Hu Xiaoping. Research on the Quality Standard of Talent Training in Financial Management Specialty [J]. China Market, 2016(05). 
[2] Wang Xiaopu. Investigation and Analysis of Market Recognition and Demand of Financial Management Specialty in Beijing, Tianjin and Hebei Region [J]. Economic Outlook the Bohai Sea, 2016(10).

[3] Jie Maohua, Wu Qian. Investigation and Research on Undergraduate Talent Cultivation of Financial Management Specialty--Based on the Three-dimensional Questionnaire of Teachers, Students and Employers [J]. Communication of Finance and Accounting, 2013(03).

[4] Xu Weishuang. Research on the Innovation of Practice Teaching Model of Accounting Specialty Based on Professional Ability Cultivation under the Background of Application-oriented Transformation [R], 2018.

[5] Wang Pei. Reflections on the Development of Financial Management Specialty -- a Sense of Visiting School in Baylor University in the United States [J]. China University Teaching, 2015(01).

[6] Wu Keping. Problems and Countermeasures in Talent Cultivation Mode of Financial Management Specialty in Local Universities under the Background of Transformation [J]. Journal of Yichun University, 2016(04).

[7] Luo Fukai. Research on Undergraduate Talent Training Program for Financial Management Specialty [J]. Finance Research, 2017(01).

[8] Li Ying, Tao Yuanlei, Li Ejiao. Research on the Training Mode of Applied Innovative Talents in Financial Management Specialty [J]. Commercial Accounting, 2014(06).

[9] Li Zhitang. Discussion on Specialization and Professionalization of Talent Cultivation in Accounting and Financial Management Specialty [J]. Commercial Accounting, 2017(01). 